\begin{tabular}{|c|c|c|}
\hline 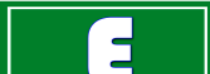 & International Journal of Current Research in & \\
\hline & Biosciences and Plant Biology & \\
\hline $\begin{array}{l}\text { EXCI } \\
\text { PUBBI }\end{array}$ & $\begin{array}{r}\text { ISSN: 2349-8080 (Online) • Volume } 3 \bullet \text { Number } \\
\text { Journal homepage: } \underline{w w w . i j c r b p . c o m}\end{array}$ & \\
\hline
\end{tabular}

\title{
Performance of Green Fruit Yield and Quality of Different Chilli Genotypes in Black Soil
}

\author{
Puttapalli Raja Sekhar ${ }^{1 *}$ and S.M. Bhoyar ${ }^{2}$ \\ ${ }^{1}$ Department of Soil Science and Agricultural Chemistry, Uttar Banga Krishi Viswavidyalaya, Pundibari, Cooch Behar, \\ West Bengal, India \\ 2Department of Soil Science and Agrilcultural Chemistry, Dr. Panjabrao Deshmukh Krishi Vidyapeeth, Akola, Maharashtra, \\ India \\ *Corresponding author.
}

\begin{abstract}
A field experiment was undertaken during Kharif-2013-14 at Dr. PDKV, Akola in RBD with twenty chilli genotypes as treatment, fertilized with common RDF and package of practices. Significant yield performance of genotypes GCL 5-6, G-4, G-5 and Surya was recorded for green as well as dry chillies. Average yield of fresh green chilli ranged from 6.2 to $20.3 \mathrm{q} \mathrm{ha}^{-1}$ and after drying, their weight reduced between 0.58 to $1.69 \mathrm{q} \mathrm{ha}^{-1}$ and their wet to dry per cent varied from 7.27 to $13.19 \%$. Quality parameters viz., ascorbic acid and capsaicin content in chilli fruits was increased with maturity of the fruits. The content of capsaicin and ascorbic acid in green chilli fruit powder varied from 67.55 to $121.95 \mathrm{mg} 100 \mathrm{~g}^{-1}$ sample and 0.50 to $0.83 \%$, respectively. Significantly highest 0.83 percent capsaicin was noted in green fruits of genotype G-5 which was also significantly highest in ascorbic acid content in green $\left(121.95 \mathrm{mg} 100 \mathrm{~g}^{-1}\right)$. On the basis of capsaicin content green fruits of G-5 and ACL-4 were pungent. Furthermore, it was noted that the after harvest of chilli genotypes mean fertility status (N $0.030 \%, \mathrm{P} 16.58$ $\mathrm{kg} \mathrm{ha}^{-1}$ and $\mathrm{K} 229.86 \mathrm{~kg} \mathrm{ha}^{-1}$ ) of soil was decline over initial status ( $0.031 \%$, P 17.27 $\mathrm{kg} \mathrm{ha}^{-1}$ and $\mathrm{K} 288.85 \mathrm{~kg} \mathrm{ha}^{-1}$ ) under common RDF. The data revealed the significant mining of soil nutrients by chilli crop to meet out its nutritional requirement.
\end{abstract}

\section{Introduction}

Chilli is a crop of tropical and sub-tropical regions and requires a warm humid climate. Though, chilli can be grown in many types of soils, well-drained loamy soils rich in organic matter are best suited for its cultivation. Many varieties of chilli have been recorded in India, varying in shape, colour, size and pungency. Chilli, one of the most important commercial spices crop and is widely used universal spice, named as wonder spice. Different varieties are cultivated around the world for varied uses like vegetables, pickles, spice and condiments. Chillies are integral and most important ingredient in many different cuisines around the world, as it adds pungency, taste, flavour and colour to dishes. Chillies stimulate saliva and gastric juices which help for digestion. They are used in the preparation of natural colouring agents, cosmetics and pharmaceuticals etc. Chilli is raised over an area of 1832 thousand hectares in the world, with a production of 2959 thousand tons. India is the world leader in chilli production followed by China and Pakistan (Anon., 2004). Indian chillies are considered to be world famous for its colour and pungency. The demand for natural pigments of chillies is increasing as it is extensively used in organic food colours and offer good potential for export. Chillies are 
rich source of vitamins $\mathrm{C}$ and $\mathrm{A}$ with plenty of minerals. Capsorubins constitute about $60-70 \%$ of the total pigments. Chilli powder has tremendous demand for chilli alkaloids 'capsaicin' worldwide for multiple uses from food to pharmaceutical preparations. Now-a-days capsaicin is being studied as an effective treatment for sensory nerve fiber disorders, including pain associated with arthritis, psoriasis and diabetic neuropathy. Significant reduction in paw inflammation was also studied in animals fed with capsaicin diet.

\section{Materials and methods}

A field experiment on different promising chilli genotypes was conducted during the kharif, 2013-14 with the consideration of twenty chilli genotypes as twenty treatments to evaluate chilli genotypes in terms of yield and quality under semi-arid condition of Vidharbha region in Maharashtra state at Dr. PDKV, Akola. Amongst 20 chilli genotypes under study, 14 were the Dr. PDKV, Akola genotypes (i.e. $\mathrm{T}_{7}$ to $\mathrm{T}_{20}$ ) and rest of six were the popular promising genotypes from various sources i.e. IARI New Delhi, Guntur, Gujarat, MPKV Rahuri and Pvt. Company genotype. The experiment was laid out in randomized block design (RBD) in three replications with twenty treatments (i.e. chilli genotypes). The soil of experimental site was medium to deep black having clay content 51.22 per cent classified it in clay texture. The initial analysis indicated that, soils are slightly alkaline in reaction having electrical conductivity $0.56 \mathrm{ds} \mathrm{m}^{-1}$ and medium in organic carbon content $\left(5.0 \mathrm{~g} \mathrm{~kg}^{-1}\right)$. As regards of fertility status the soils are very low in total nitrogen $(0.031 \%)$ which reflects on very low content in available nitrogen $\left(132.16 \mathrm{~kg} \mathrm{ha}^{-1}\right)$ and also low in available phosphorus (17.22 $\mathrm{kg} \mathrm{ha}^{-1}$ ) however moderately high in available potash $(288.85 \mathrm{~kg}$ $\left.\mathrm{ha}^{-1}\right)$.

Common cultural practices and common RDF was given to all chilli genotypes. During land preparation, FYM @ $25 \mathrm{t} \mathrm{ha}^{-1}$ was applied to field and common recommended dose of N:P:K (150:50:50 kg ha ${ }^{-1}$ ) was common for all treatments i.e., chilli genotypes. Healthy and uniform six week old chilli seedlings were transplanted in main field with a spacing of $60 \times 45 \mathrm{~cm}$. Entire $\mathrm{P}_{2} \mathrm{O}_{5}$ and $\mathrm{K}_{2} \mathrm{O}$ were applied at the time of transplanting through DiAmmonium Phosphate (DAP) and Muriate of Potash (MOP). Whereas, remaining 50\% Nitrogen was supplied through Urea in after two months of transplanting. Two foliar sprays of humic acid ( $1 \mathrm{ml}$ per lit) were given at 15 days interval during flowering stage. Protective irrigation was given to crop as and when required to maintain the moisture content in soil. Mature green fruits selected from the tagged plants were harvested in three pickings from each treatment and their yield observations were recorded till the final harvest. From the green chillies harvested at fourth picking, ascorbic acid content was determined using 2, 6 dichlorophenol indophenol dye (AOAC, 1997).

Capsaicin content (\%) of green fruits is measured by spectroscopic method as described by Sadasivam and Manickam (1996). Colour chart was used to determine the colour group of green chilli fruits as per colour index of The Royal Horicultural Society Chart. Soil pH was measured by a combined glass calomel electrode (Jackson, 1967). Organic carbon was determined by wet oxidation method. Total $\mathrm{N}$ was determined by modified Kjeldahl method. Phosphorus was determined by Olsen's method (Watanabe and Olsen, 1965). Potassium was determined by Flame photometric method (Jackson, 1967). The data collected from the experimental field was analysed statistically following the procedure as described by Panse and Sukhatme (1967).

\section{Results and discussion}

\section{Fresh and dried green chilli fruit yield and their wet to dry per cent}

In all total 20 chilli popular and local genotypes were tested for yield of fresh green chilli followed by drying for recovery of dried chilli fruits and data obtained is presented in Table 1. Data revealed that there was a significant difference among the chilli genotypes as regards fresh green fruit yield of chilli which was reflected on the significant differences in the dry green chilli yield and its weight to dry percentage. The yield of fresh green chilli from different genotypes ranged from 6.2 to $20.3 \mathrm{q} \mathrm{ha}^{-1}$ and after drying, their weight reduced between 0.58 to $1.69 \mathrm{q} \mathrm{ha}^{-1}$ and their wet to dry per cent varied from 7.27 to $13.19 \%$. Significantly higher fresh green fruit yield of $20.3 \mathrm{q} \mathrm{ha}^{-1}$ was recorded in the genotype Surya followed by GCL 5-6 (17.6 q ha $\left.{ }^{-1}\right)$. Thus from the data, it can be revealed that only two genotypes under study viz., Surya and GCL 5-6 recorded higher yield of green chilli i.e., above $17 \mathrm{q} \mathrm{ha}^{-1}$ and eight genotypes viz., G-4, G-5, Gujarat long, ACL-1, ACL-2, ACL-3, ACL-4 and GCL 5-5 recorded green chilli yield between 10 to $15 \mathrm{q} \mathrm{ha}^{-1}$ and remaining 10 genotypes recorded comparative lower yield of green chilli fruits. Similar results as regards of green chilli fruits were reported by Talukder and Jana (2009) in Terai region of West Bengal. After controlled drying of green chilli 
fruits, significantly highest dried green chilli fruit yield was obtained from G-4 and G-5 and was also numerically similar i.e. $1.69 \mathrm{q} \mathrm{ha}^{-1}$. The wet to dry percent of chilli genotype was worked out and it was noted that significantly highest $13.19 \%$ wet to dry ratio was recorded by genotype G-5 followed by Jayanti Selection (11.66\%), G-4 (11.52\%) and BCL 5-8 $(10.50 \%)$. Higher wet to dry ratio means the higher recovery of dry concentrate of chilli which generally related to the thin/thickness of pericarp, seed content in fruit and strong/weak spike which are the inherent genetical characteristics of the genotype. In general it was noted that, popular genotype Surya gave the highest yield of the fresh green chilli fruit but recovery of the dried green fruit was more in Guntur genotypes G-4 and G-5. Among Dr. PDKV genotypes GCL 5-6 recorded higher yield of fresh green chilli but higher wet to dry percent was recorded in genotype Jayanti selection.

Table 1. Yield of fresh green chilli fruits and their wet to dry per cent and quality.

\begin{tabular}{lllllll}
\hline S. No. & Genotypes & $\begin{array}{l}\text { Yield of fresh } \\
\text { green chilli } \\
\left(\mathbf{q} \mathbf{~ h a}^{-1}\right)\end{array}$ & $\begin{array}{l}\text { Yield of dry } \\
\text { green chilli } \\
\left(\mathbf{q} \mathbf{~ h}^{-1}\right)\end{array}$ & $\begin{array}{l}\text { Wet to dry } \\
\text { Per cent }\end{array}$ & $\begin{array}{l}\text { Green chilli } \\
\text { Ascorbic acid } \\
(\mathbf{m g} / \mathbf{1 0 0 g})\end{array}$ & $\begin{array}{l}\text { Capsaicin } \\
(\mathbf{\%})\end{array}$ \\
\hline $\mathrm{T}_{1}$ & Pusa Jwala & 7.0 & 0.77 & 10.45 & 108.76 & 0.51 \\
$\mathrm{~T}_{2}$ & G-4 & 14.4 & 1.69 & 11.52 & 67.55 & 0.75 \\
$\mathrm{~T}_{3}$ & G-5 & 12.7 & 1.69 & 13.19 & 121.77 & 0.83 \\
$\mathrm{~T}_{4}$ & Gujarat long & 10.1 & 9.09 & 9.00 & 121.61 & 0.61 \\
$\mathrm{~T}_{5}$ & Agnirekha & 6.2 & 0.58 & 9.36 & 108.54 & 0.72 \\
$\mathrm{~T}_{6}$ & Surya & 20.3 & 1.48 & 7.27 & 95.54 & 0.56 \\
$\mathrm{~T}_{7}$ & Jayanti & 7.9 & 0.78 & 9.64 & 121.73 & 0.76 \\
$\mathrm{~T}_{8}$ & Jayanti Selection & 7.0 & 0.72 & 11.66 & 121.95 & 0.67 \\
$\mathrm{~T}_{9}$ & Malewada local & 7.7 & 0.87 & 11.00 & 108.98 & 0.67 \\
$\mathrm{~T}_{10}$ & Bhiwapuri local & 7.4 & 0.81 & 10.43 & 94.80 & 0.57 \\
$\mathrm{~T}_{11}$ & ACL-1 & 12.3 & 1.14 & 10.01 & 81.25 & 0.76 \\
$\mathrm{~T}_{12}$ & ACL-2 & 11.7 & 1.09 & 9.06 & 108.24 & 0.83 \\
$\mathrm{~T}_{13}$ & ACL-3 & 10.8 & 1.15 & 11.42 & 108.62 & 0.49 \\
$\mathrm{~T}_{14}$ & ACL-4 & 10.8 & 1.15 & 10.42 & 94.48 & 0.80 \\
$\mathrm{~T}_{15}$ & GCL 5-4 & 6.4 & 0.61 & 9.04 & 81.26 & 0.59 \\
$\mathrm{~T}_{16}$ & GCL 5-5 & 13.8 & 1.14 & 8.04 & 94.53 & 0.62 \\
$\mathrm{~T}_{17}$ & GCL 5-6 & 17.6 & 1.20 & 8.61 & 108.22 & 0.61 \\
$\mathrm{~T}_{18}$ & GCL 5-7 & 8.0 & 0.89 & 9.60 & 108.66 & 0.61 \\
$\mathrm{~T}_{19}$ & BCL 5-8 & 6.3 & 0.68 & 10.50 & 108.80 & 0.72 \\
$\mathrm{~T}_{20}$ & BCL 10-9 & 7.6 & 0.65 & 8.40 & 121.71 & 0.62 \\
\hline $\mathrm{SE}(\mathrm{m} \pm$ ) & & 0.620 & 0.041 & 0.065 & 0.412 & 0.006 \\
$\mathrm{CD}$ at 5\% & 1.742 & 0.116 & 0.182 & 1.163 & 0.017 \\
\hline
\end{tabular}

\section{Quality performance}

As per ascorbic acid content in green fruits of various chilli genotypes under study revealed that Dr. PDKV chilli genotype Jayanti Selection was recorded highest

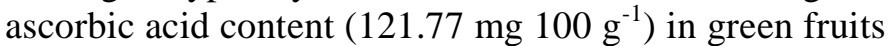
among all genotypes. Similar results were reported by Datta and Jana (2011) while testing of different chilli genotypes with respect to their stability at terai zone of west Bengal. Furthermore, higher recovery of the ascorbic acid may be due to the drying of green chillies of all genotypes under study by using Dr. PDKVProcessing technology under controlled temperature and pressure as the ascorbic acid was degraded by higher temperatures and the drying temperature of the said method was $60^{\circ} \mathrm{C}$. Significantly, highest capsaicin $0.83 \%$ content in green fruits powder was recorded in chilli genotypes G-5 and ACL-2 followed by ACL-4 $(0.80 \%)$. Similar result was reported by Prasath et al. (2006) while studying the evaluation of chilli germplasm. Significant difference existed among different chilli genotypes under this study with respect to capsaicin content in green fruits powder and it varied from 0.50 to $0.83 \%$. According to colour index of chart (Table 2), fresh fruits of twelve chilli genotypes viz., Pusa Jwala, G-4, G-5, Gujarat long, Agnirekha, Jayanti, Malewada local, Bhiwapuri local, GCL 5-4, GCL 5-5, GCL 5-7, BCL 5-8 were recognized under the Green group (137-A to 143-B); whereas, fresh fruit of other eight genotypes namely Surya, Jayanti Selection, ACL1, ACL-2, ACL-3, ACL-4, GCL 5-6, BCL 10-9 were recognized under the Yellow Green colour group (144A to 144-C). The green chilli powders of sixteen chilli genotypes come under the colour Yellow Green group 
(146-B to 152-D) and remaining four viz., Jayanti, Bhiwapuri local, ACL-2 and BCL 5-8 were recognized under the colour grey brown group (199-A). Slight discoloration of green chilli fruits after drying in to powder i.e., Green to yellow green may be due to the fact that the controlled low temperature drying of fresh chillies by Dr. PDKV-Technology, which gives bright colour to the finish product.

Table 2. Colour index of green and green chilli powder of different genotypes (The Royal Horticultural Society chart).

\begin{tabular}{|c|c|c|c|c|c|}
\hline \multirow{2}{*}{ S. No. } & \multirow{2}{*}{ Genotypes } & \multicolumn{2}{|l|}{ Green chilli } & \multicolumn{2}{|c|}{ Green chilli powder } \\
\hline & & Colour Group & Index & Colour Group & Index \\
\hline $\mathrm{T}_{1}$ & Pusa Jwala & Yellow green & 144-C & Yellow green & $146-\mathrm{C}$ \\
\hline $\mathrm{T}_{3}$ & G-5 & Green & $141-\mathrm{A}$ & Yellow green & 146-B \\
\hline $\mathrm{T}_{4}$ & Gujarat long & Green & 137-A & Yellow green & $152-\mathrm{A}$ \\
\hline $\mathrm{T}_{5}$ & Agnirekha & Green & 143-B & Yellow green & 146-B \\
\hline $\mathrm{T}_{7}$ & Jayanti & Green & 143-A & Grey brown & 199-A \\
\hline $\mathrm{T}_{8}$ & Jayanti Selection & Yellow green & 144-A & Yellow green & $146-\mathrm{C}$ \\
\hline $\mathrm{T}_{9}$ & Malewada local & Green & 143-B & Yellow green & 146-B \\
\hline $\mathrm{T}_{10}$ & Bhiwapuri local & Green & $143-\mathrm{A}$ & Grey brown & 199-A \\
\hline $\mathrm{T}_{15}$ & GCL 5-4 & Green & 139-A & Yellow green & 147-B \\
\hline $\mathrm{T}_{16}$ & GCL 5-5 & Green & $143-\mathrm{A}$ & Yellow green & $152-\mathrm{C}$ \\
\hline $\mathrm{T}_{17}$ & GCL 5-6 & Yellow green & $144-\mathrm{C}$ & Yellow green & $152-\mathrm{B}$ \\
\hline $\mathrm{T}_{18}$ & GCL 5-7 & Green & 139-A & Yellow green & 147-B \\
\hline $\mathrm{T}_{19}$ & BCL 5-8 & Green & $143-\mathrm{A}$ & Grey brown & 199-A \\
\hline $\mathrm{T}_{20}$ & BCL 10-9 & Yellow green & $144-\mathrm{A}$ & Yellow green & $146-\mathrm{C}$ \\
\hline
\end{tabular}

Different chilli genotypes recorded non-significant influence on the soil reaction, electrical conductivity and organic carbon content in the soil. The organic carbon content in the soil after harvest of chilli genotypes was observed between 5.03 to $5.93 \mathrm{~g} \mathrm{~kg}^{-1}$. Data as regarded for total nitrogen content in soil after harvest of chilli genotypes was non-significant. Whereas, significant differences in available phosphorus and available potassium content were observed amongst chilli genotypes. Furthermore, it was noted that the mean average content of total nitrogen, available phosphorus and available potash content in black soil was lower i.e., $0.030 \%, 16.58 \mathrm{~kg} \mathrm{ha}^{-1}$ and $229.86 \mathrm{~kg} \mathrm{ha}{ }^{-1}$ when fertilized with common recommended dose of NPK fertilizers. The data revealed the significant mining of available phosphorus and potash from the soil.

\section{Conflict of interest statement}

Authors declare that they have no conflict of interest.

\section{References}

Anonymous, 2004, Production of fruit and vegetable crops. In; Annual Report of Govt. of India. Publication Division, Ministry of Information and Broadcasting Department. $66 \mathrm{p}$.

AOAC, 1997. Official Methods of Analysis.11 ${ }^{\text {th }}$ Edn. Association of Official Analytical Chemists, Washington, DC. 420 p.

Datta, S., Jana, J. C., 2011. Performance of chilli (Capsicum annum) genotypes under Terai agroclimatic region of West Bengal. Ind. J. Agric. Sci. 81(6), 567-570.

Jackson, M. L. 1967. Soil Chemical Analysis. Prentice Hall of India Private Limited, New Delhi.

Prasath, D., Ponnuswami, V., Muralidharan, V., 2007. Evaluation of chilli (Capsicum spp.) germplasm for extractable colour and pungency. Ind. J. Genet. 67(1), 9798.

Sadasivam, S., Macickam, A., 1992. Biochemical Methods. $2^{\text {nd }}$ Edn. New Age International (P) Limited Publishers, New Delhi and TNAU, Coimbatore, India. pp.193-210.

Panse, V. G., Sukhatme, P. V., 1967. Statistical Methods for Agricultural Workers. ICAR Pub., New Delhi. 
Talukder, B., Jana, J.C., 2009. Integrated nutrient management for better growth, yield and quality of green chilli (Capsicum annuиm) in terai region of West Bengal. Ind. J. Agric. Sci. 79(8), 600-603.
Watanabe, F.S., Olsen, S.R., 1965. Test of an ascorbic acid method for determining phosphorus in water and $\mathrm{NaHCO}_{3}$ extracts from soils. Soil Sci. Soc. Amer. Proc. 29, 677678.

\section{How to cite this article:}

Raja Sekhar, P., Bhoyar, S.M., 2016. Performance of green fruit yield and quality of different chilli genotypes in black soil. Int. J. Curr. Res. Biosci. Plant Biol. 3(3), 34-38.

doi: http://dx.doi.org/10.20546/ijcrbp.2016.303.007 